Case Report

\title{
Successful One Stage Operation for Giant Frontonasal Encephalocele in a Very Young Child: A Case Report
}

\author{
DM Arman ${ }^{1}$, Sheikh Muhammad Ekramullah², Sudipta Kumer Mukherjee ${ }^{3}$, \\ Md. Rahimullah Chowdhury ${ }^{4}$, Md. Abdul Quddus Mia', Kazi Nur Asfia ${ }^{6}$
}

\begin{abstract}
${ }^{1}$ Assistant Professor, Department of Paediatric Neurosurgery, National Institute of Neurosciences and Hospital, Dhaka, Bangladesh; ${ }^{2}$ Professor and Head, Department of Paediatric Neurosurgery, National Institute of Neurosciences and Hospital, Dhaka, Bangladesh; ${ }^{3}$ Assistant Professor, Department of Paediatric Neurosurgery, National Institute of Neurosciences and Hospital, Dhaka, Bangladesh; ${ }^{4}$ Assistant Professor, Department of Oral and Maxillofacial surgery, Comilla Medical College, Comilla, Bangladesh; ${ }^{5}$ Junior Consultant (Neuroanaesthesia), Department of Anaesthesia, National Institute of Neurosciences and Hospital, Dhaka, Bangladesh; ${ }^{6}$ Assistant Professor, Department of Neuroanaesthesia, National Institute of Neurosciences and Hospital, Dhaka, Bangladesh
\end{abstract}

[Received: 21 September 2017; Revised: 6 November 2017; Accepted: 11 December 2017; Published: 1 January 2018]

\begin{abstract}
Encephalocele is defined as protrusion of cranial contents like meninges and cerebral tissue beyond the normal confines of the skull through a defect in the cranium. It is one form of a neural tube defect as are anencephaly and spina bifida. There are 2 main types of encephalomeningocele, frontoethmoidal and occipital, according to the location of the defect. The frontoethmoidal type defect, which is located in the area of the frontal and ethmoidal bones. The authors present a case of frontonasal encephalocele in a very young child. [Journal of National Institute of Neurosciences Bangladesh, 2018;4(1): 58-62]
\end{abstract}

Keywords: Frontonasal encephalocele; giant; child; one stage operation

Correspondence: Dr. D.M. Arman, Assistant Professor, Department of Paediatric Neurosurgery, National Institute of Neurosciences and Hospital, Sher-E-Bangla Nagar, Agargaon, Dhaka, Bangladesh; Email: armandmdr@yahoo.com; Cell no.: +8801745771780 Conflict of interest: There is no conflict of interest relevant to this paper to disclose.

Contribution to authors: Arman DM, Ekramullah SM, Mukherjee SS, Chowdhury MR have clinically diagnosed the case the mange the case. Arman DM has written the manuscript. Asfia KN and Mia MAQ have revised the manuscript.

How to cite this article: Arman DM, Ekramullah SM, Mukherjee SK, Chowdhury MR, Mia MAQ, Asfia KN. Successful One Stage Operation for Giant Frontonasal Encephalocele in a Very Young Child: A Case Report. J Natl Inst Neurosci Bangladesh, 2018;4(1): 58-62.

Copyright: (C2018.Arman et al. Published by Journal of National Institute of Neurosciences Bangladesh. This article is published under the Creative Commons CC BY-NC License (https://creativecommons.org/licenses/by-nc/4.0/). This license permits use, distribution and reproduction in any medium, provided the original work is properly cited, and is not used for commercial purposes.

\section{Introduction}

Encephalocele is defined as protrusion of cranial contents like meninges and cerebral tissue beyond the normal confines of the skull through a defect in the cranium. The population incidence of this congenital anomaly is estimated to vary from 1 per 300 to 1 per 10000 live births ${ }^{1-4}$. In respect to the incidence, cranial dysraphism, particularly encephaloceles, is far less common compared to its spinalcounterpart, namely, myelomeningocele, accounting for only 8 to $19 \%$ of all dysraphism ${ }^{4-9}$.

It is one form of a neural tube defect as are anencephaly and spina bifida $^{10}$. There are 2 main types of encephalo-meningocele, frontoethmoidal and occipital, according to the location of the defect. The frontoethmoidal type defect, which is located in the area of the frontal and ethmoidal bones, is exclusively common in Southeast $\mathrm{Asia}^{11}$. There has been no consensus about the etiology, prognosis-related classification, or surgical strategy for encephalomeningocele.

The aim of surgical treatment is to restore the functional brain tissue in the cranial cavity by performing dural repair with the correction of bone defect and restoration of esthetic facial appearance safely and successfully in a single stage. We had managed a case successfully in a one stage operation for frontonasal encephalocele in a very young child.

\section{Case Presentation}

A 9 month-old male child was admitted to our hospital, presented with a protruding softswellingwith a wide base 

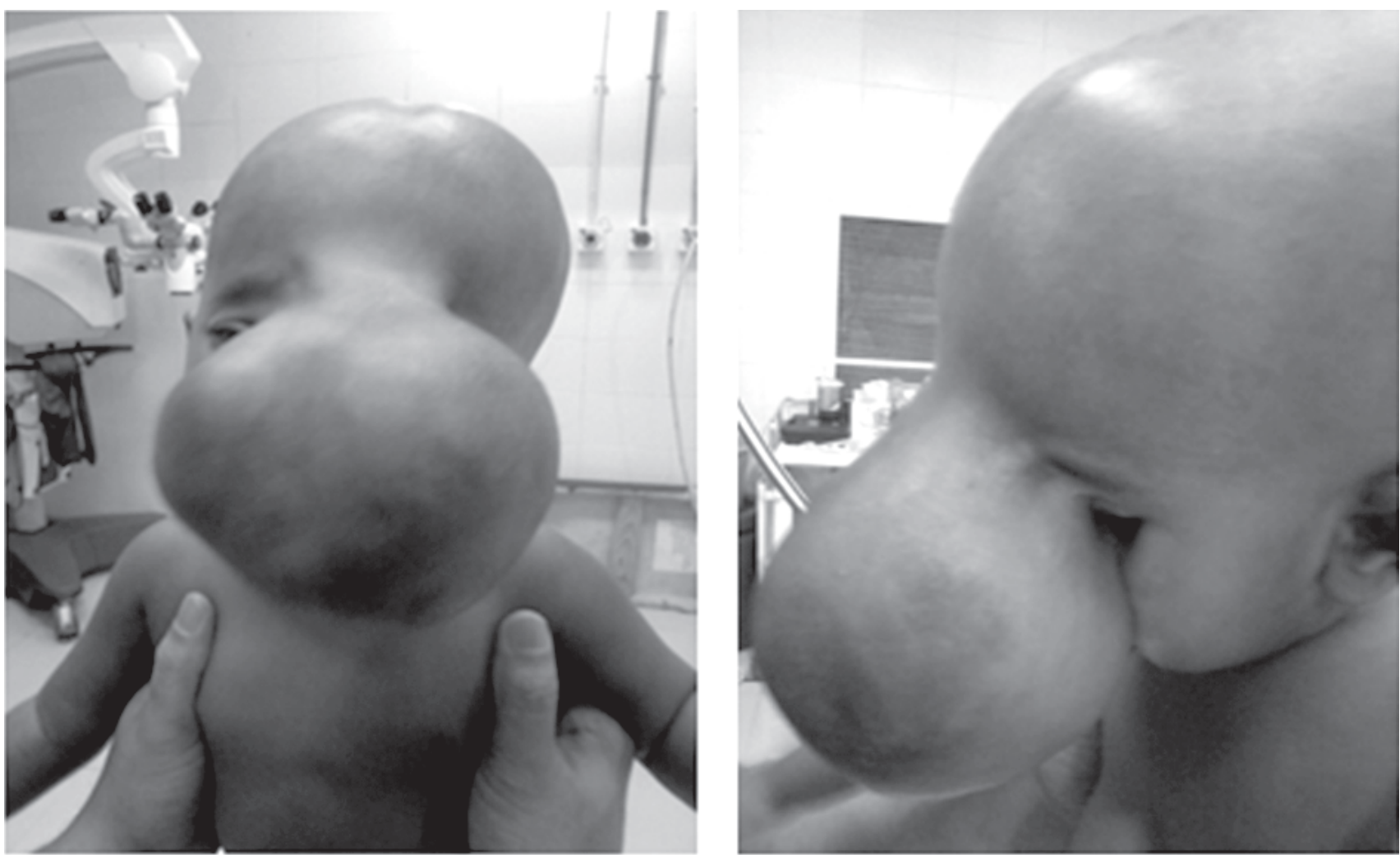

Figure I: preoperative photograph of 9-month-old male child with Frontonasal encephalocele

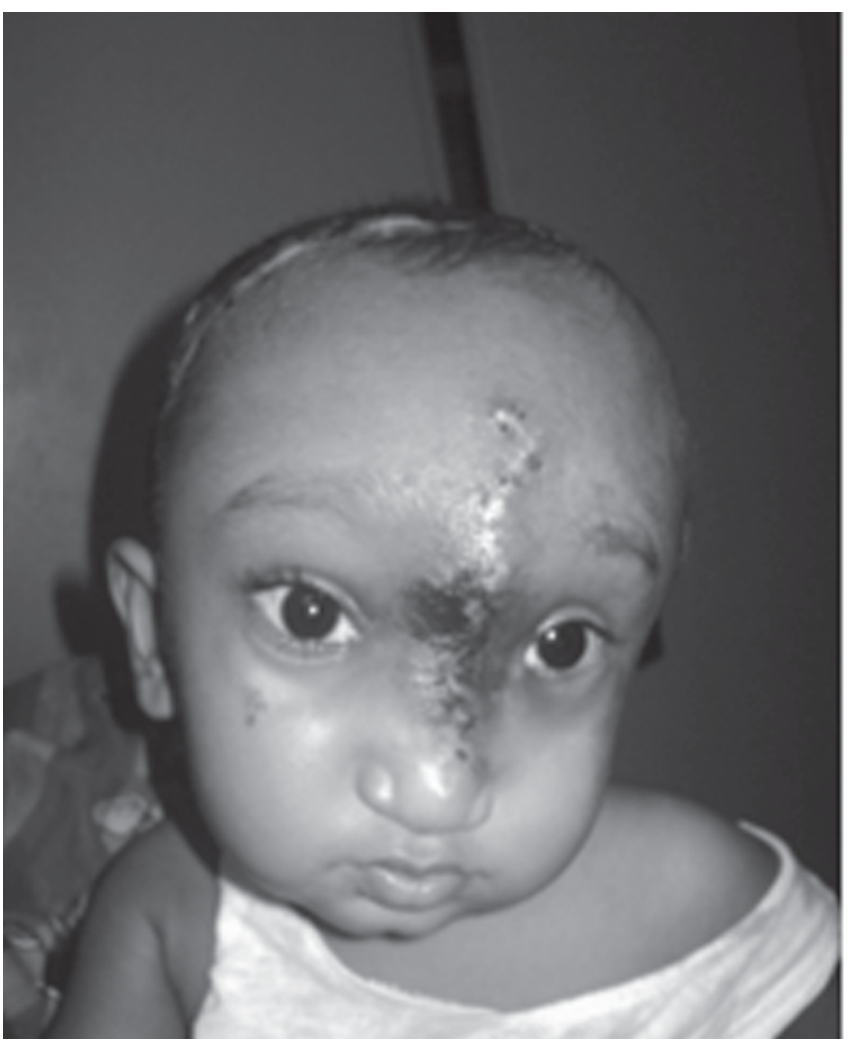

Figure II: Postoperative photograph (after 3 weeks of operation)

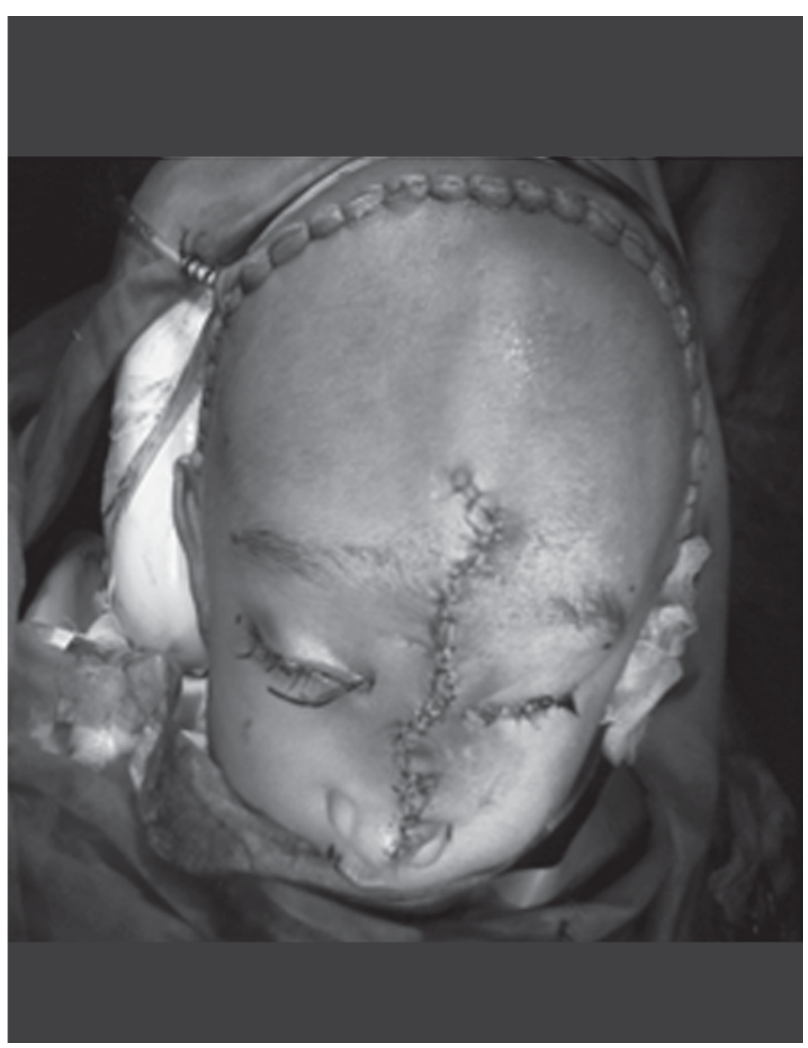

Figure III: Intraoperative photograph 
between the eyes (Figure I, II). According to his mother's description, he had been born with the facial swelling. It had slowly enlarged as he grew up.There were no complaints with regard to vision. No congenital anomalies were mentioned in his siblings. The physical examination revealed non-pulsatile pedunculated swelling near the nasal bridge, between themedial canthus with underlying bony defect,interorbital hypertelorism, long-nose deformity and medial canthal dystopia. The neurological status revealed no abnormalities.

\section{Neuroimaging studies}

He was investigated with CT-scan of the head andMRI of brain that showed a defect in the anterior cranial base involving the crista galli and between frontal and nasal bone. The defect directly communicated with the anterior cranial fossa through which herniated brain could be seen extending through nasal bridge. The size and anatomical location of the lesion were noted. Associated findings, such as, head size, any underlying hydrocephalus were also noted.

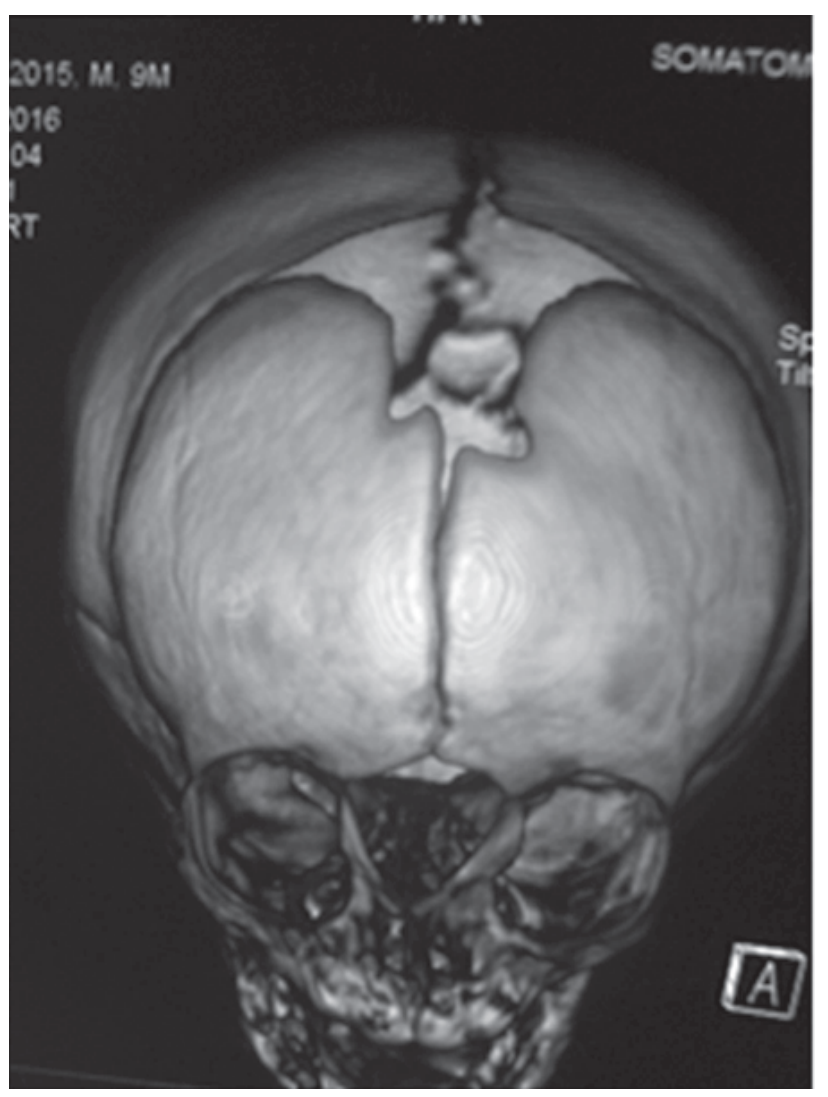

Figure IV: 3D CT scan of head Showing external bone defect
Operation and postoperative courses: In this cases a combined approach was used was scheduled for single stage surgery for repair of dura. Craniotomy and repair from inside was done. We made a bicoronal scalp incision down to the anterior of the tragus. A paranasal skin incision was made in a reversed Y-shape because of the bilateral herniated masses in order to remove any redundant skin. The scalp was reflected to expose frontal bone, both supra orbital rims nasal bridge with bony defect. A typical bifrontal craniotomy and a $\mathrm{T}$ shaped frontonasal osteotomy were done to obtain adequate exposure to the encephalomeningoceles. Supra orbital rim was removed. A satisfactory extradural exposure all around the herniating glioting brain was thus achieved. The margins were freed all around the bony defect. The skull defects over the inner wall of the orbit and ethmoidal sinus were located, and the herniated dura sac and the degenerative brain tissue it contained were resected. Watertight and durable closure of the dural defect was achieved. The nasal bridge was reconstructed with split frontal bone. All areas were fixed with 2-0 prolene. The medial canthus was repositioned with prolene 3-0 stay sutures. After

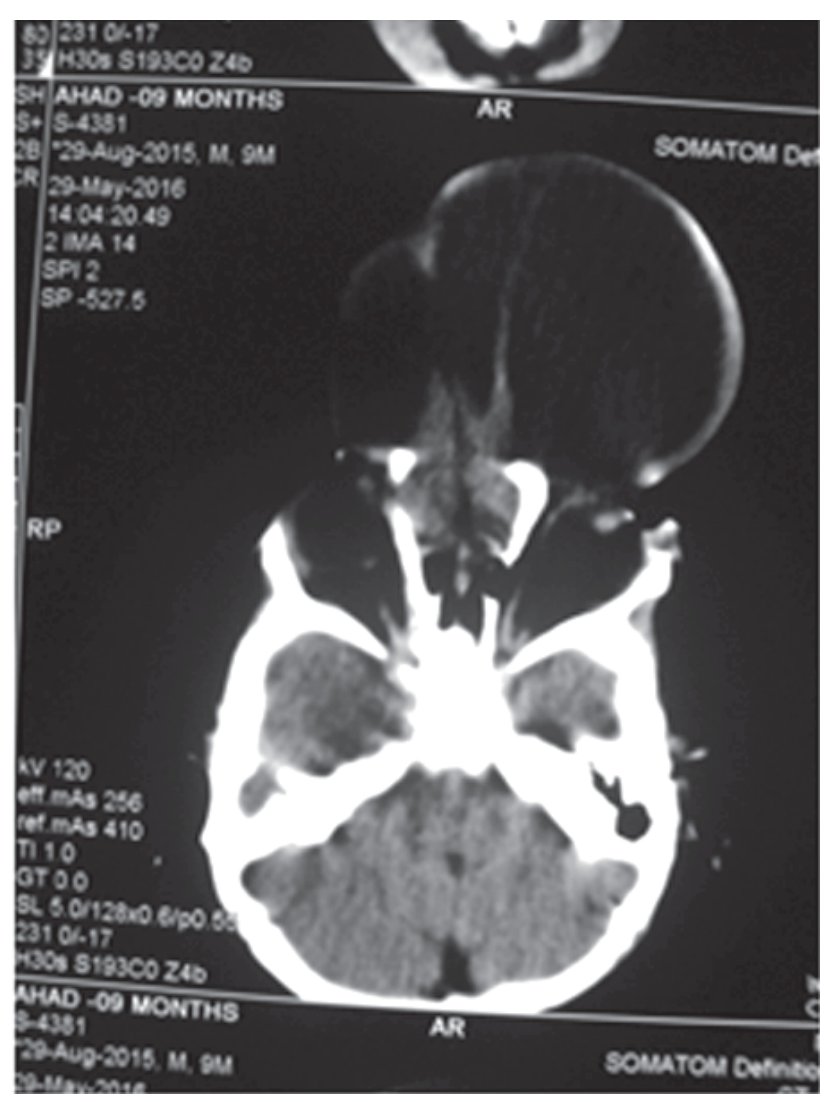

Figure V: CT scan axial view showing anterior cranial base defect 


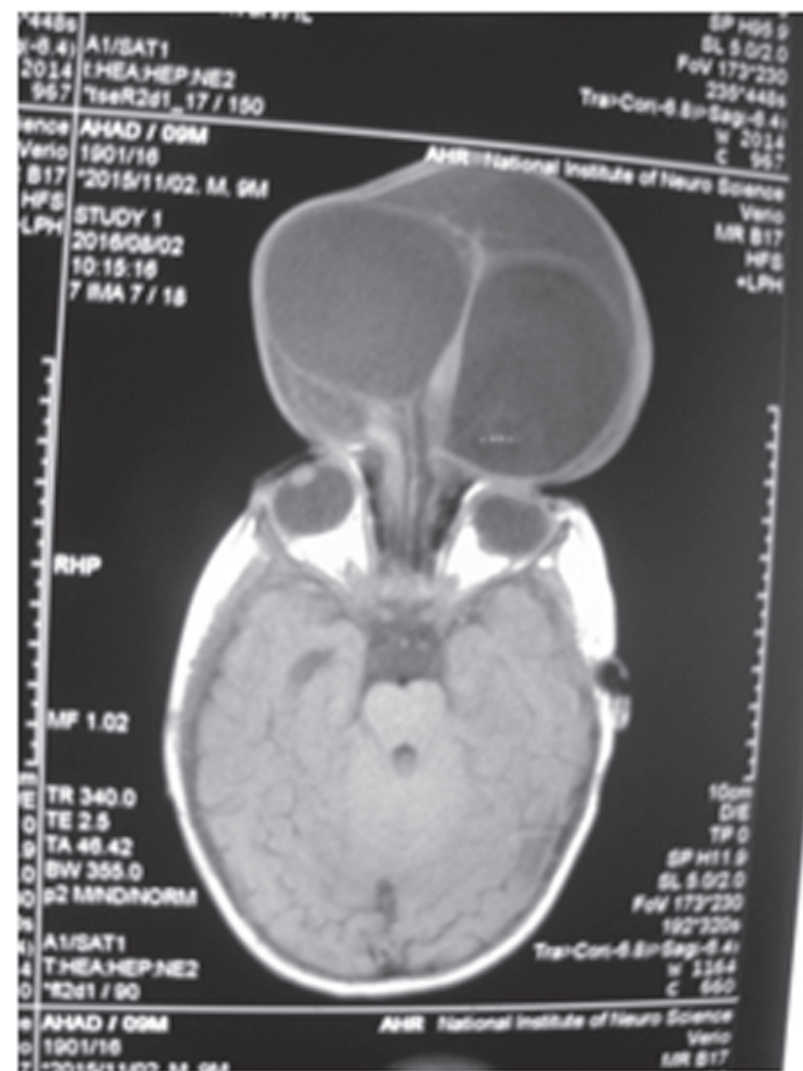

Figure VI: MRI of brain Showing encephalomeningocele

achieving haemostasis,wounds were closed in layers. Postoperatively, patient recovered uneventfully except there was subgaleal CSF collection in postoperative period (3rd POD) managed by single aspiration. A good cosmetic result had been achieved after operation (Figure III).

\section{Discussion}

From the anatomic aspect, the most common sites for encephaloceles are occipital and fronto-nasal regions. In Asia and Africa, there is a predominance of the fronto-nasal group while $80-90 \%$ are found in the occipital region in the Western Hemisphere. Approximately $70 \%$ of occipital encephaloceles occur in females, but there is no sex predominance noted in the frontobasal type. The incidence of hydrocephalus in patients with encephaloceles is reported to be about $50.0 \%$. In planning the strategy of management of encephalocele, one needs to take into consideration the site, size, contents, state of CSF pathway, neurological status, associated anomalies and overall general condition of the patient. In both our cases, there was a fronto-orbito-nasal defect extending posteriorly up to crista galli with mild hypertelorism and cosmetic deformity.

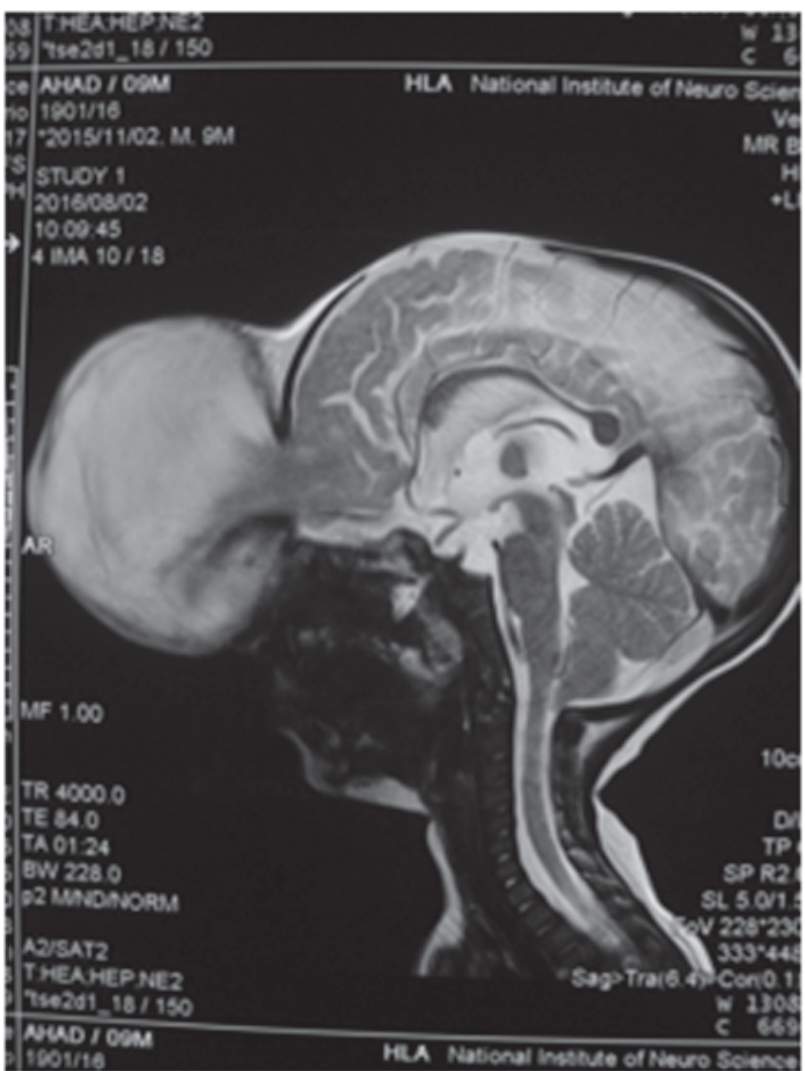

Figure VII: MRI of brain sagittal view showing anterior cranial defect

The principle of repair is analogous to the management of hernias in general surgery, which includes dissection of the sac, isolation of the neck, adequate closure at the neck and reinforcement. The herniated part of the brain is usually gliosed and non-viable and can usually be safely amputated. Dural defect should be closed in a watertight fashion, using graft if necessary. In our case, watertight and durable closure of the dural defect was achieved by an autologous pericranial graft and fibrin glue. Ideally, reinforcement of bony defect with bone graft (split cranium, split rib, or acrylic) will prevent reprotrusion through the defect. Reconstruction of bony abnormalities may be necessary at times for better cosmetic results. Associated hydrocephalus should be treated by shunting before managing the encephalocele. As mentioned before, surgical approaches for encephaloceles, based on its location and type, can be direct, indirect or both. In 2 cases, our operative approach involved combined approach (bifrontal craniotomy and direct repair) and were performed in collaboration with the Maxillofacial surgeon. We performed a typical bifrontal craniotomy with a T-shaped osteotomy for 1-stage reconstruction and obtained adequate exposure in order to perform dura repair and the encephalomeningocele resection. 
The end result of encephalocele surgery is usually not determined by the neurosurgical procedure per se, but by the underlying brain involvement and presence or absence of other congenital defects. In long-term follow up, cases with anterior defect have better prognosis and more than half have normal intelligence quotient (IQ) $)^{12}$.

Instead of the traditional 2-stage correction by preliminary disconnection and subsequent extracranial correction of the facial deformity ${ }^{13}$, a 1-stage operation has become the standard treatment ${ }^{14-15}$. Most Neurosurgeons and craniofacial surgeons prefer the combined nasal-coronal approach with a frontal craniotomy because of the wide exposure ${ }^{14}$. On the other hand, the frontal bone flap can also be remodeled to eliminate the trigonocephalic bulge ${ }^{16}$, repair any external skull defects, and restore an esthetic appearance such as with nasal augmentation.

\section{Conclusion}

Encephalocele is a relatively uncommon neurosurgical entity largely seen in the pediatric population. Treatment of this condition can be rewarding if properly managed early. Occipital type may be approached without opening the cranium, while sincipital and basal encephaloceles usually require craniotomy. In this paper we present our experience in the operative management of frontonasal encephalocele with good outcome and also share our recommendation in technical consideration for surgical approaches.

Disclaimer: The authors report no conflict of interest concerning the materials or methods used in this study or the findings specified in this paper.

Acknowledgments: The authors would like to thank Dr. Soumen, Prof. Sk.Md.Sader Hossain (Professor and Head, Clinical neurosurgery), Prof. Md. Badrul Alam (Professor of Neurology and Joint Director) and Prof. Quazi Deen Mohammad (Professor of Neurology and Director)

\section{References}

1. Caviness CS Jr, Evrard P: Occipital encephalocele: A pathologic and anatomic analysis. Acta Neuropath 1975;32:245-255

2. Karch SB, Urich H. Occipital encephalocele: A morphological study. J Neurol Sci 1972;15:89-112

3. Lorber J. The prognosis of occipital encephalocele. Develop Med Child Neurol 1967;13:75-86

4. Mealey J Jr, Dzenitis AJ, Hockey AA. The prognosis of encephaloceles. J Neurosurg 1970;32:209-218

5. Barrow N, Simpson DA. Cranium bifidum: Investigation, prognosis and management. AustPaediat J 1996;2:20-26

6. Eckstein HB, Macnab GH. Myelomeningocele and hydrocephalus: the impact of modern treatment. The Lancet. 1966;287(7442):842-5

7. Fisher RG, Uihlein A, Keith HM. Spina bifida and cranium bifidum: Study of 530 cases. Mayo Clin Proc1952;27:33-38

8. Matson DD. Neurosurgery of infancy and childhood, Ed. 2. Springfield III: Charles C Thomas, 1969

9. Schwidde JT. Spina bifida: Survey of 225 encephaloceles, meningoceles and myeomeningoceles. Amer J Dis Child 1952;84:35-51

10. Botto LD, Moore CA, Khoury MJ, Erickson JD. Neuraltube defects. N Engl J Med 1999; 341:1509-1519

11. Suwanwela C, Suwanwela N: A morphological classification of sincipital encephalo-meningoceles. J Neurosurg 1972; 36:201-211

12. Shilpakar SK, Sharma MR. Surgical management of encephaloceles. J Neuroscience. 2004;1:45-8

13. Tandon PN. Meningoencephalocoeles. Acta Neurol Scand 1970; 46:369

14. David DJ. Cephaloceles: Classification, pathology, and management-A review. J Craniofac Surg 1993; 4:192- 202

15. Forcada M, Montandon D, Rilliet B: Frontoethmoidal cephaloceles: Transcranial and transfacial surgical treatment. J Craniofac Surg 1993; 4:203-209

16. Holmes AD, Meara JG, Kolker AR, Rosenfeld JV, Klug GL. Frontoethmoidal encephaloceles: Reconstruction and refinements. J Craniofac Surg 2001;12:6-18 